\title{
Risk estimates for neonatal myotonic dystrophy
}

\author{
A GLANZ AND F C FRASER
}

From the McGill Center for Human Genetics, and the Department of Medical Genetics, The Montreal Children's Hospital, Montreal, Canada.

SUMMARY Children who inherit the autosomal dominant gene for myotonic dystrophy from their mother rather than their father may develop the severe neonatal type rather than the late onset type. The families of 22 neonatal type probands and 59 late onset type probands were studied to determine the risk of occurrence and recurrence of the neonatal type.

The frequency of the neonatal type in sibs of neonatal type probands was $29 \%$, or $37 \%$ if cases of neonatal deaths are counted as affected. This is significantly higher than the $6 \%$ of the neonatal type found in the offspring of affected women not ascertained through a child with the neonatal type. These data suggest that certain women carrying the gene for myotonic dystrophy are predisposed to have children affected with the neonatal type rather than the late onset type. The female near relatives of these women do not seem to share this predisposition. The data should be useful for genetic counselling.

Myotonic dystrophy is an autosomal dominant disorder with a wide range of expression that exists in several clinical forms. The so-called 'adult onset' type, which may, in fact, manifest some signs at birth, is characterised by weakness, myotonia, muscular wasting, ptosis, cataracts, and, in males, frontal baldness and testicular atrophy. Some gene carriers may have only the characteristic cataracts, or no clinical signs but only abnormal electromyographic findings. ${ }^{1}$ Within this type, there may be subdivisions, with type 2 having an earlier mean age of onset, more marked facial weakness, and milder, more patchy limb weakness than type $1,{ }^{2}$ though this distinction remains to be confirmed.

The neonatal type (sometimes referred to as the 'congenital' type ${ }^{3}$ ) is characterised by polyhydramnios, severe hypotonia at birth, muscular atrophy, oedema, facial diplegia, tent shaped upper lip, episodes of respiratory distress, feeding difficulties, and, sometimes, contractures. ${ }^{3-6}$ If the mother is mildly affected, the baby may be diagnosed as having neonatal asphyxia and the relationship to myotonic dystrophy may go unrecognised. ${ }^{6}$ After a stormy neonatal period the clinical status usually improves gradually as the hypotonia lessens and the respiratory problems diminish. Developmental milestones are delayed and mental retardation is common, IQs ranging from 40 to $80 .{ }^{7}$ Later, these children develop the features of the adult form, which tends to have an

Received for publication 29 June 1983. Accepted for publication 9 November 1983. earlier onset and greater severity than in persons with the 'adult onset' type.

Curiously, the neonatal type occurs only when the mutant gene is received from the mother. ${ }^{8}$ In the few cases reported in which the father was affected, the disease was not unequivocally neonatal. Harper ${ }^{8}$ estimated the proportion of neonatally affected sibs of neonatal cases as $\mathbf{0 . 2 4}$ if neonatal deaths are counted as unaffected, and 0.45 if they are counted as affected. The present paper will provide an estimate of the risk that the offspring of females with myotonic dystrophy will have the neonatal type, revise the estimate of recurrence risk for the neonatal type, and approach the question of whether the probability of having a child with the neonatal type differs from one affected mother to another.

\section{Materials and methods}

The families studied in this report were collected as part of a larger investigation into various aspects of myotonic dystrophy. Of the 81 families studied, 27 were personally interviewed. Information on the remaining 54 families was obtained by chart review. The families seen were referred by the Neuromuscular Clinic of The Montreal Children's Hospital, or the Department of Neurogenetics of the Montreal Neurological Hospital, or were previously known to our Medical Genetics Department. Information on the other families was kindly made available to us by centres in Halifax, Sherbrooke, Calgary, Vancouver, and Seattle. 
Families from the Montreal area were contacted and seen either at the Montreal Children's Hospital or the Montreal Neurological Hospital. In some instances, social conditions or travelling difficulties prevented the family from coming to the hospital and home visits were made. Every effort was made to see all available relatives of the proband. At the initial examination, a complete family history was taken and, when necessary, the diagnosis was subsequently confirmed by slit lamp examination and electromyography.

Special care was taken to determine whether the proband was of the neonatal or late onset type. When this was not obvious from the history, hospital records of the perinatal history were obtained. Each diagnosis had been confirmed by a neurologist on the basis of hypotonia in the neonatal period, the myopathic facies, difficulties with respiration and feeding, and, if the patient survived long enough, appearance of the late onset disease. There were no equivocal cases. All probands had a positive family history, sometimes recognised retrospectively.

\section{Results and discussion}

Twenty-two families were ascertained through a neonatal proband and 59 through a late onset proband. For the purpose of estimating risks, the two groups are treated separately. The data are classified into the following groups for segregation analysis (table 1).

(1) Sibs of neonatal probands. All of these had an affected mother (row 1).

(2) Sibs of late onset probands with an affected mother (row 3).

(3) Offspring of affected female collateral relatives of the neonatal probands (row 2). These were mostly sisters of the proband's mother. In this and the next group, ascertainment bias was adjusted for by excluding the offspring of the first affected ancestor in each family that was in the direct line of descent to the proband. Proband sibships were also excluded. Like sexed twins of unknown zygosity (all of whom were concordant) were counted as $1 \cdot 5$ subjects.

(4) Offspring of affected female relatives of late onset probands (row 4).

The results show that the frequency of the neonatal type of myotonic dystrophy was higher in the offspring of affected mothers who had already had a neonatally affected child (proband excluded) than in the offspring of affected mothers who had not yet had a neonatally affected child. The frequency of recurrence was $29.2 \%(7 / 24)$ in the sibs of neonatal probands (row 1). This was strikingly and significantly higher $(p<0.001)$ than the frequency of the neonatal form in the sibs of late onset probands $(5 \%)$ or the offspring of mothers who were not ascertained through a child with the neonatal form (rows 2,3 , and 4 ), a total of $24 / 409$ or $5.9 \%$. If perinatal deaths are counted as neonatal cases, the risk for the neonatal type rises to $37 \cdot 5 \%(9 / 24)$ and $7 \cdot 1 \%(29 / 409)$ respectively.

These findings suggest that the propensity for affected women to have offspring of the congenital type is related to the maternal uterine environment of some, but not all, female heterozygotes. One might question whether the observed excess resulted from preferential referral of multiplex sibships. If this were the case, one would expect probands in multiplex families to be the last of the affected sibs rather than the first, but this is not so. In eleven such families, the proband was born before the other cases in seven and after in four.

One may then ask whether the propensity to have neonatal type offspring is familial. In the offspring of affected female relatives of neonatal probands (row 2), the data do not support this. The proportion of neonatal to late onset cases is $5: 42$ or $10.6 \%$ of cases that are neonatal compared to $16: 76$ or $17.4 \%$ in the offspring of affected female relatives of the late onset probands (row 4). The difference is not significant and is in the direction contrary to the hypothesis. Furthermore, the proportions of neonatal cases in all offspring of affected relatives are $5.3 \%$ and $6.3 \%$ respectively. Thus, there is no

TABLE 1 Proportions of neonatal, late onset, and unaffected relatives of females with myotonic dystrophy.

\begin{tabular}{|c|c|c|c|c|c|c|c|c|c|}
\hline & \multicolumn{2}{|c|}{ Unaffected } & \multicolumn{6}{|c|}{ Affected } & \multirow[b]{3}{*}{ Total } \\
\hline & \multirow[b]{2}{*}{ No } & \multirow[b]{2}{*}{$\%$} & \multicolumn{2}{|l|}{ Late } & \multicolumn{2}{|c|}{ Neonatal } & \multicolumn{2}{|c|}{ Either } & \\
\hline & & & No & $\%$ & No & $\%$ & No & $\%$ & \\
\hline \multicolumn{10}{|l|}{ Neonatal probands } \\
\hline Sibs & 9 & $37 \cdot 5$ & 8 & $33 \cdot 3$ & 7 & $29 \cdot 2$ & 15 & $62 \cdot 5$ & 24 \\
\hline Offspring of affected female relatives & $47 \cdot 5$ & $50 \cdot 3$ & 42 & $44 \cdot 4$ & 5 & $5 \cdot 3$ & 47 & $49 \cdot 7$ & $94 \cdot 5$ \\
\hline \multicolumn{10}{|l|}{ Late onset probands } \\
\hline Sibs & 40 & $66 \cdot 7$ & 17 & $28 \cdot 3$ & 3 & 5 & 20 & $33 \cdot 3$ & 60 \\
\hline Offspring of affected female relatives & $162 \cdot 5$ & $63 \cdot 9$ & 76 & $29 \cdot 9$ & 16 & $6 \cdot 3$ & 92 & $36 \cdot 1$ & $254 \cdot 5$ \\
\hline Total & 259 & & 143 & & 31 & & 174 & $40 \cdot 2$ & 433 \\
\hline
\end{tabular}


evidence that the tendency for certain females to have offspring with neonatal myotonic dystrophy is familial. This somewhat surprising finding leaves open the question of what it is that makes some female heterozygotes more prone to have offspring of the neonatal type than others. Perhaps a genetic difference making some females more likely to have offspring with the neonatal type gets so diluted in the comparison of female relatives of the susceptible and non-susceptible females that it is obscured by random variation. Only a larger sample will tell.

The recurrence risk estimates derived from the present study can be compared to those compiled from published reports. If the pedigrees published by various authors are grouped (table 2), the risks for sibs of neonatal probands are $57 \%$ of affected children or $22 \%$ of all sibs. These figures agree fairly closely with our figures of $47 \%$ and $29 \%$ respectively (table 1 , row 1 ). As the neonatal type of myotonic dystrophy was not recognised before 1960,9 information on the frequency of this type cannot reliably be gathered from older reports. The recognition of the neonatal type spurred the publication of affected families ascertained through the neonatal type at the expense of families ascertained through the late onset type. The risk figures obtained in our series of late onset probands are, therefore, not comparable to those of any previous study. An indirect estimate of the risk of the neonatal type was made by Harper. ${ }^{8}$ Using his series of patients gathered before the special significance of the neonatal type was recognised, and classifying the patients by symptoms retrospectively, he concluded that $9 \%$ of the offspring of women with myotonic dystrophy will be severely affected and survive, $12 \%$ will die neonatally or be stillborn, and $29 \%$ will become affected later in life. His group of severely affected surviving offspring is probably analogous to our neonatal myotonic dystrophy series, and our estimate of $5.9 \%$ is not significantly different from his estimate of $9 \%$.

TABLE 2 Published risk estimates for sibs of neonatal probands.

\begin{tabular}{|c|c|c|c|}
\hline \multirow[t]{2}{*}{ Author (year) } & \multicolumn{2}{|l|}{ Affected } & \multirow[t]{2}{*}{ Unaffected } \\
\hline & Neonatal & Late onset & \\
\hline Dodge et al (1965) 10 & 1 & 1 & 8 \\
\hline Pruzanski (1966) $)^{11}$ & $\mathbf{0}$ & 0 & 1 \\
\hline Calderon (1966) 7 & 0 & 0 & 2 \\
\hline Gordon and Hilson (1967) & 0 & $\mathbf{0}$ & 1 \\
\hline Watters and Williams $(1967)^{5}$ & 1 & 0 & 8 \\
\hline Dyken and Harper (1973) 13 & 10 & 9 & 9 \\
\hline Fried et al (1975) 14 & 1 & 1 & 0 \\
\hline Simpson (1975) 15 & 1 & 0 & 0 \\
\hline Harper $(1975)^{8}$ & 14 & 9 & 46 \\
\hline Sarnat and Silbert (1976) ${ }^{16}$ & $\mathbf{0}$ & 1 & 2 \\
\hline Total & 28 & 21 & 77 \\
\hline$\%$ & 22 & 17 & 61 \\
\hline
\end{tabular}

In conclusion, we estimate that the rate of recurrence of neonatal myotonic dystrophy is $29 \% \stackrel{\vec{P}}{\rightarrow}$ for affected mothers. Affected mothers with no 0 previous neonatally affected children face approxi- $\overline{\bar{O}}$ mately a $6 \%$ risk of having a child with the neonatal $\frac{\bar{c}}{\partial}$ type. These risk estimates will be of value in the $\stackrel{\mathbb{Q}}{\propto}$ management and genetic counselling of families with myotonic dystrophy.

We are grateful to Dr Eva Andermann for making $\overrightarrow{\vec{H}}$ available to us cases seen at The Montreal Neurological Hospital, Dr Fred Andermann who carried $\overline{\overline{3}}$ out many of the neurological assessments, Dr To Kirkham for the ophthalmological examinations, $\underset{-}{\sim}$ and Dr Bernard Lemieux (Université de Sherbrooke), $\omega$ Dr Elizabeth Winsor (Dalhousie University), Dr $\vec{\infty}$ Judy Hall (then in Seattle), Dr Brian Lowry (Cal- o gary), and Dr Patrick MacLeod (then at the Univer- $\frac{\circ}{工}$ sity of British Columbia), who made available their $\vec{c}$ files on affected families.

\section{References}

1 Bundey S, Carter CO. Early recognition of heterozygotes $\stackrel{\infty}{\oplus}$ for the gene for dystrophia myotonica. $J$ Neurol Neurosurg Psychiatry 1970;33:279-93.

2 Bundey S. Clinical evidence for heterogeneity in myotonic dystrophy. J Med Genet 1982;19:341-8.

3 Harper PS. Congenital myotonic dystrophy in Britain. I. Clinical aspects. Arch Dis Child 1975;50:505-13.

4 Bell DB, Smith DW. Myotonic dystrophy in the neonate. J Pediatr 1972;81:83-6.

5 Watters GV, Williams TW. Early onset myotonic $\frac{0}{3}$ dystrophy. Arch Neurol 1967;17:137-52.

- Pearse RG, Howeler CJ. Neonatal form of dystrophia myotonica. Arch Dis Child 1979;54:331-8.

7 Calderon R. Myotonic dystrophy: a neglected cause of mental retardation. $J$ Pediatr 1966;68:423-31.

8 Harper PS. Congenital myotonic dystrophy in Britain. II. Genetic basis. Arch Dis Child 1975;50:514-21.

9 Vanier TM. Dystrophia myotonica in childhood. Br Med $J$ 1960;ii:1284-8.

10 Dodge PR, Gamstorp I, Byers RK, Russell P. Myotonic dystrophy in infancy and childhood. Pediatrics $1965 ; 35$ : 3-19.

11 Pruzanski W. Variants of myotonic dystrophy in pre- $D$ adolescent life. Brain 1966;89:563-8.

12 Gordon N, Hilson D. Myotonic dystrophy of occurrence in childhood. Br J Clin Pract 1967;21:537-40.

13 Dyken P, Harper PS. Congenital dystrophia myotonica. Neurology (Minneap) 1973;23:465-73.

14 Fried K, Pajewski M, Mundel G, Caspi E, Spira R. Thin ribs in neonatal myotonic dystrophy. Clin Genet 1975;7: 417-20.

15 Simpson K. Neonatal respiratory failure due to myotonice dystrophy. Arch Dis Child 1975;50:569-71.

16 Sarnat HB, Silbert SW. Maturation arrest of fetal muscle $\stackrel{\mathcal{D}}{+}$ in neonatal myotonic dystrophy. Arch Neurol 1976;33: 466-74.

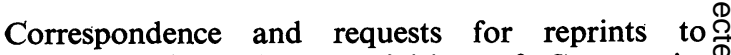
Professor F C Fraser, Division of Community $\stackrel{D}{\square}$ Medicine, Faculty of Medicine, Memorial University, St John's, Newfoundland, Canada A1B 3V6. 